\title{
Myomectomy for degenerated myoma
}

\author{
Shilu Adhikari, Archana Amatya, Geeta Gurung, Ashma Rana \\ Department of Obstetrics and Gynecology, \\ Tribhuvan University Teaching Hospital
}

\begin{abstract}
:
Degenerative changes in myomas found in the reproductive age group in day to day life is much lower than reported and in this respect we present as unusual case of myoma size $15 \times 20 \mathrm{~cm}$ with myxoid degeneration in a 23 year old nulliparous lady presenting with menorrhagia, increased frequency of micturition who underwent myomectomy even after cystic changes was seen on USG and CT scan; this case indicating the importances of organ preserving surgery in young women.
\end{abstract}

Key words: cystic changes, lump in lower abdomen, menorrhagia, myoma, myomectomy

\section{Introduction}

Myomas are the commonest benign tumours in the reproductive age, rarely affecting women below 30 years for which the incidence is less than $4 \%$, however, there are reports of this tumor in age of 15 years too. ${ }^{1}$ Secondary changes occur in about $65 \%$ of myomas, in the descending order of hyaline degeneration (63\%), myxoid degeneration (19\%), calcification (8\%) and cystic changes $(4 \%)$. These myomas usually have a typical sonographic appearance. With cystic degeneration, however, the sonographic findings may be completely uncharacteristic. ${ }^{2}$

Radiological intervention has a role in determination of the size and status of myoma whether undegenerated or not. ${ }^{3,4}$

Myoma may resemble an ovarian cyst if degenerated. ${ }^{5}$ And these degenerated myoma may rupture giving rise to hemoperitoneum. ${ }^{6}$

A case of a myoma in a young woman, which had been diagnosed as ovarian cyst and had been advised an emergency surgery, is presented here.

\section{Case report}

A 23 year old recently married nulliparous lady presented to us in the Gynaecology OPD with complaints of menorrhagia for the past 5 months along with a mass in the lower abdomen for 3 months and increased frequency of micturition. She had consulted another practitioner who had advised her for immediate hysterectomy in the view that the mass might rupture any time as it was thought to be an ovarian tumour.
Clinical examination revealed a mass about $15 \mathrm{~cm}$ x 20 $\mathrm{cm}$ in the hypogastrium and umbilical region extending to the right iliac fossa, which was soft and cystic in consistency with restricted mobility above downwards. Per vaginal examination detected a mass in the fundal region of the uterus, soft in consistency which could be easily moved along with the cervix. Ultrasound showed an enlarged uterus with myometrial cystic changes suggestive of cystic degeneration (Fig. 1). CT scan revealed similar findings. She was very anaemic ( $\mathrm{Hb} 6.7 \mathrm{gm} \mathrm{\% )}$ ) hence she was transfused 2 pints of packed cells prior to myomectomy. She was also explained that she might need hysterectomy during the procedure in case of difficulty.

Intraoperatively a huge myoma was present in the fundal and anterior wall of the uterus measuring $15 \mathrm{~cm}$ x $20 \mathrm{~cm}$ (fig 2). Myomectomy could be performed successfully despite the myoma being extra soft with

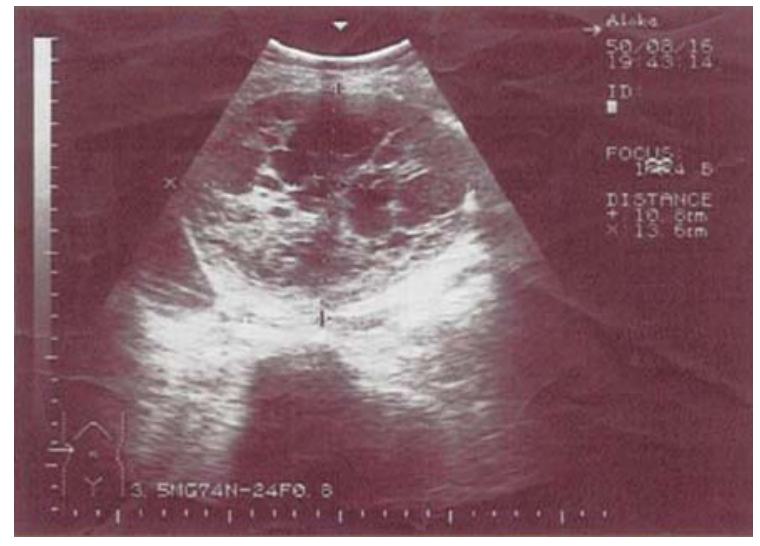

Figure 1: Ultrasound showing an enlarged uterus with myometrial cystic changes suggesting cystic degeneration 


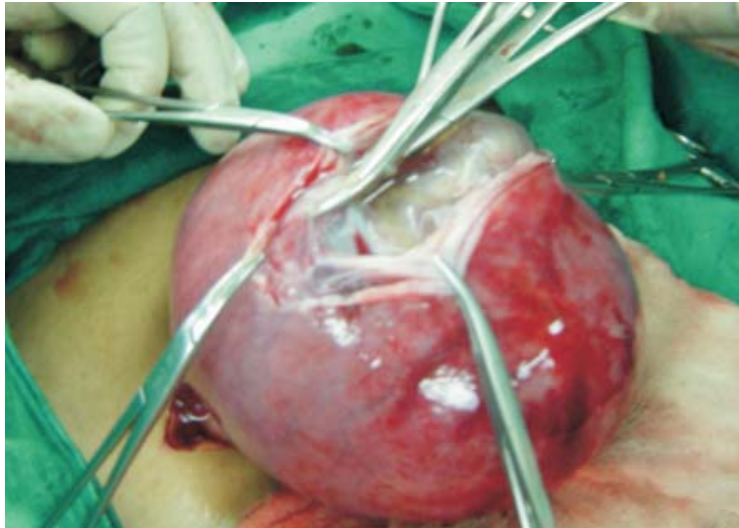

Figure 2: Myomectomy being performed

cystic degenerative changes and the conservation of the uterus was possible. Cut section showed cystic spaces containing fluid in the myoma and loss of the typical whorled appearance (fig 3). She was discharged on the $6^{\text {th }}$ postoperative day. Histopathology report confirmed myoma with myxoid changes.

\section{Comment}

Myomas are not uncommon gynaecological tumours in the reproductive age group, moreover, degenerative changes occurring in the myomas are also not uncommon, but sometimes a myoma may occur in unusual age group met with the type of unusual degeneration (myxoid). This was a myoma in a 23 year old nullipara presenting with menorrhagia, increased frequency of micturition and $15 \mathrm{~cm}$ x $20 \mathrm{~cm}$ lump abdomen extending from the hypogastrium to umbilical region and showing cystic changes on USG and CT scan, who underwent myomectomy.

While myomas are most often straightforward in their presentation and management, they can undergo various kinds of asymptomatic degeneration that drastically alters their appearance and muddies the process of diagnosis. Intramyometrial cystic disorders (cystic adenomyosis, myoma with cystic degeneration and vestigial cysts) and vascular disorders (intramyometrial and parametrial vascular malformations) are rare, but a sound knowledge is required to optimize their management, which is based on surgery and interventional vascular techniques. ${ }^{2}$ Pathologically myxoid myomas are smooth muscle tumours in which myxoid material separates the tumour cells. They are soft and translucent. Histologically they contain abundant amorphous myxoid material present between the smooth muscle cells. The margins of myxoid myomas are circumscribed but neither cytological atypia nor mitotic figures are present. We report this case of myoma with cystic changes in a young adult woman, where preserving

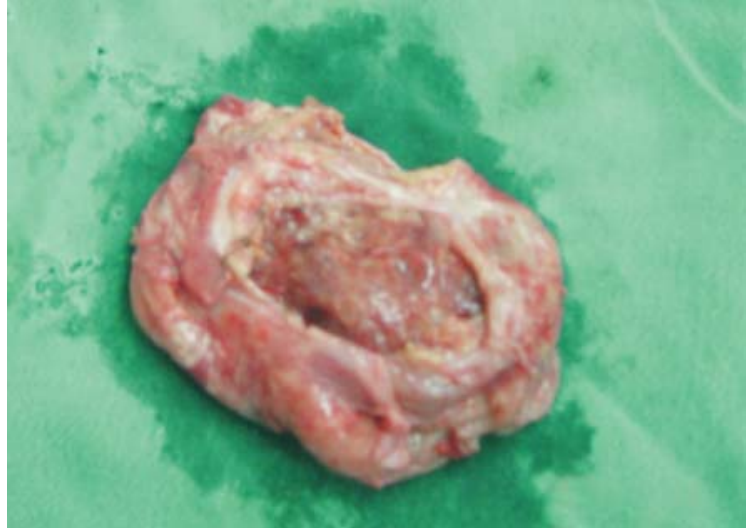

Figure 3: Cut section showing cystic spaces with fluid within myoma and loss of typical whorled appearance

her fertility was the most important aim. Some recent studies have shown quick conception that occurred in more than half of the women after myomectomy with $1 / 4$ who were delivered of live babies and these were in patients with no other apparent cause of infertility. ${ }^{7}$

In Verkauf's study ${ }^{8}$ of 280 cases of myomectomies, conception occurred in more than half of the women who were previously pregnant. In patients with no other apparent cause of infertility $59.5 \%$ did conceive. Among those who had other problems, 50\% conceived after myomectomy. A review of 9 abdominal myomectomy reports by Vercellini ${ }^{9}$ and colleagues indicated similar results.

Interestingly most of the pregnancies $(86 \%)$ have occurred within 3 years from the surgery, allowing sufficient time for conception to occur before the likelihood of recurrence $7.5 \%$.

When present in the younger age group we should try to preserve a potentially functioning uterus capable of future reproduction. A pregnancy in myomatous uterus is not without danger. ${ }^{10}$

\section{Conclusion}

Uterine myomas are a prevalent issue for women of reproductive age. With this case of myomectomy in case of degenerated myoma, the importance of preserving the uterus in young women with myoma is depicted.

\section{References}

1. Fields KR, Neinstein LS. Uterine myomas in adolescents: case reports and a review of the literature. J Pediatr Adolesc Gynecol. 1996 Nov;9(4):195-8. 
2. Carlan SJ, O'Brien WF, Holbrook J, Mastrogiannis D, Vaughn V. Cystic degeneration of a leiomyoma masquerading as a postoperative abscess. Am J Perinatol. 1992 May; 9(3):175-8.

3. Marret H, Chevillot M, Giraudeau B; Study Group of the French Society of Gynaecology and Obstetrics (Ouest Division). Factors influencing laparoconversions during the learning curve of laparoscopic myomectomy. Acta Obstet Gynecol Scand 2006; 85(3):324-9.

4. Okizuka H, Sugimura K, Takemori M, Obayashi C, Kitao M, Ishida T. MR detection of degenerating uterine leiomyomas. J Comput Assist Tomogr. 1993 Sep-Oct; 17(5):760-6

5. Kulshrestha R, Lakhey M, Rani S. Massive cystic degeneration of a uterine leiomyoma presenting as an ovarian cyst: a case report. Indian J Pathol Microbiol. 2003 Jan; 46(1):86-8.

6. Varras M, Antoniou S, Samara Ch, Frakala S, Angelidou-Manika Z, Paissios P. Intraperitoneal haemorrhage secondary to perforation of uterine fibroid after cystic degeneration. Unusual CT findings resembling malignant pelvic tumor: case report. Eur J Gynaecol Oncol 2002; 23(6):5658.

7. Mara M, Fucikova Z, Kuzel D, Sosna O, Dundr P, Kriz P, Koryntova D.

Enucleation of intramural uterine fibroids in women at fertile age: midterm results of prospective clinical trials. Ceska Gynekol. 2006 Jan;71(1):16-24.

8. Verkauf B. Myomectomy for fertility enhancement and preservation, fertile Steril 1992;58:1.

9. Vercellini P, Bocciolone L, Rognoni et al, Fibroids and Infertility. Adv Repro Endocrinol 1992; 4: 47.

10. Kitao K, Ohara N, Funakoshi T, Moriyama T, Morita H, Kitazawa S, Maruo T. Consumptive coagulopathy that developed in a pregnant woman with degenerated uterine leiomyoma: case report. Clin Exp Obstet Gynecol. 2005;32(4):250. 